\title{
LOX-1 biology and targeting LOX-1 in cardiovascular diseases
}

\author{
Shijie Liu ${ }^{1,2}$ and Zufeng Ding ${ }^{1,2 *}$ \\ ${ }^{1}$ Central Arkansas Veterans Healthcare System and the University of Arkansas for Medical Sciences, Little Rock, AR 72205, USA \\ ${ }^{2}$ Key Laboratory for Biomechanics and Mechanobiology of Ministry of Education, School of Biological Science and Medical Engineering, Beihang University, \\ Beijing 100191, China
}

\begin{abstract}
Oxidized low-density lipoprotein (ox-LDL) plays a critical role in a variety of cardiovascular diseases, including atherosclerosis, hypertension and myocardial ischemia. Encoded by OLR1 gene, lectin-like ox-LDL scavenger receptor-1 (LOX-1) is the major receptor for ox-LDL at the surface of the cells. LOX-1 activation by ox-LDL, reactive oxygen species (ROS), angiotensin II and inflammatory signals causes many pathophysiological events, such as cell proliferation, apoptosis and autophagy, which are hallmarks of the atherosclerotic lesions. LOX-1 is also involved in mitochondrial DNA damage mediated inflammaotry response. All these observations support the possible contribution of LOX-1 to the pathogenesis of cardiovascular disorders, particularly atherosclerosis, indicating that targeting LOX1 may be an effective strategy for the treatment of cardiovascular diseases. This review summarizes current knowledge of LOX-1 function and possible therapeutic options targeting LOX-1 in cardiovascular diseases.
\end{abstract}

\section{Introduction}

LOX-1 was initially identified as a main receptor for ox-LDL in endothelial cells by Sawamura et al. in 1997 [1]. Further study found that LOX-1 is also expressed in other types of cells, such as smooth muscle cells, macrophages, cardiomyocytes and neurons [2-5]. Under physiological conditions, LOX-1 expression is minimal, but it can be significantly elevated by diverse stimuli, such as reactive oxygen species (ROS), ox-LDL, angiotensin II and high glucose concentration [6-9]. Interestingly, in human primary aortic or umbilical vein endothelial cells and smooth muscle cells, ox-LDL can upregulate its own receptor expression at transcriptional level in a time- and concentrationdependent manner $[10,11]$. Pretreatment of the specific antibody or siRNA directed at LOX-1 can block the upregulation of LOX-1 in response to ox-LDL. Recently, we reported that LOX-1 has a higher expression in smooth muscle cells than endothelial cells [12], consistent with the concept that smooth muscle cells play a more important role in the development of atherosclerosis. Besides atherosclerosis, LOX-1 expression is also higher in several pathological conditions, including inflammation, hypertension and myocardial ischemia [13].

Astherosclerosis is a chronic inflammatory disease that involves abnormal lipoprotein metabolism, intimal hyperplasia and the release of inflammatory factors [13]. Honjo et al. showed that LOX-1 inhibition by pretreatment with its antibody attenuated inflammatory response in rats given lipopolysaccharide (LPS), suggesting the role of LOX-1 in inflammation [14]. Kelly et al. also showed that LOX-1 inhibition decreased expression of anti-inflammatory transcription factor peroxisome proliferator-activated receptor- $\delta$ in NRK52E cells [15]. Recently, Shin et al. found that LOX-1 activation is involved in $\mathrm{NAD}(\mathrm{P}) \mathrm{H}$ oxidase-dependent superoxide formation and induction of cytokines in human endothelial cell line [16].

More and more evidence indicates that cell death, including autopgy and apoptosis, is the major modulating factor in the development of atherosclerosis. Autophagy is a highly conserved and cellular self-degradative process that response to stress espcially in starvation, responsible for the balancing sources of energy, removing misfolded proteins and recycling of damaged organelles [17]. There is high genome similarity between mitochondria and bacteria because mitochondria originally evolved from bacteria. Similar to bacteria, mitochondrial DNA (mtDNA) often contains inflammatogenic unmethylated $\mathrm{CpG}$ motifs, which triggers immune cells to recognize mtDNA as invading bacteria and induces inflammatory response [18]. Unlike cellular nuclei that have multiple mechanisms for DNA repair, mitochondria appear limited in their ability to rectify all possible forms of DNA damage. Damged mtDNA are often degraded by autophagy and other biological enzymes [3,14,27]. With cultured human THP1 macrophages, we reported that LPS induced mtDNA damage could trigger autophagy and NLRP3 inflammasome activation, and LOX1 inhibition by its siRNA transfection markedly decreased mtDNA damage and attenuated inflammatory response [3]. Similarly, with cultured human endothelial cells, we also showed that escaped damage mtDNA from autophgy could trigger TLR9 expression, while LOX-1 seems to play a critical role in this signaling pathway [6].

Similar to autophagy, apoptosis is another cell death program, a major event in the pathophysiology of atherosclerosis. Endothelial cells apoptosis results in increased vascular permeability to lipids,

Correspondence to: Zufeng Ding, Division of Cardiovascular Medicine, University of Arkansas for Medical Sciences, Little Rock, AR 72212, USA, Tel: 501-256-5558; E-mail: ZDing@uams.edu or dingzufeng@gmail.com

Key words: $L O X-1$, ox-LDL, cardiovascular disease

Received: August 05, 2016; Accepted: September 12, 2016; Published: September 15,2016 
cell proliferation and increased coagulation, while smooth muscle apoptosis may contribute to atherosclerotic plaque destabilization [19]. LOX-1 activation can induce apoptosis in many cell types, including endothelial cells, smooth muscle cells and macrophages, which are three main components of blood vessels [7]. Under physiological conditions with shear stress at 13 dynes $/ \mathrm{cm}^{2}$, LOX-1 has been shown to regulate apoptosis activity in endothelial cells by influencing apoptotic proteins cytochrome c, Bax, Bcl-2 and Bcl-xL [20]. Lu et al. [21] reported that LOX-1 inhibition by its siRNA transfection reduced L5 uptake. L5 is an electronegative component of LDL abundant in dyslipidemic, which is upregulated by LOX-1 activation and induced apoptosis. Takabe et al. [22] found that LOX-1 is invovled in ox-LDL-induced c-Jun N-terminal kinas (JNK) activation, which is one of the main signaling pathway in endothelial cell apoptosis. We [23] examined the expression of autophagy and apoptosis in human primary aortic endothelial cells and smooth muscle cells treated with ox-LDL or LPS, which furhter confirmed that LOX-1 is invovled in these two types of cell death. As expected, pretreatment with the LOX-1 inhibitor miRNA hsa-let-7g or its siRNA transfection declined proteins expression of autophagy and apoptosis. Sun et al. [24] also found that LOX-1 is invovled in smooth muscle cell apoptosis, which is mediated by ROS and nuclear factor- $\kappa \mathrm{B}(\mathrm{NF}-\kappa \mathrm{B})$ activation. Compared with apoptosis in endothelial cells and smooth muscle cells, macrophages apoptosis may contribute to enlargement of the lipid core, result in lipid accumulation and transformation into foam cells.

Atherosclerosis is the cause of myocardial ischemia and several other cardiovascular maladies. It appears that ox-LDL is more potent in the development of atherosclerosis than native LDL. The above discussion suggests strongly that ox-LDL initiates and sustains atherogeneis by ctivation LOX-1. Indeed, we first described that LOX-1 deletion reduces atherogenesis in LDLR knockout mice fed high cholesterol diet [33]. Besides atherosclerosis, human LOX1 gene has been also confirmed to be associated with several other cardiovascular diseases. Myocardial ischemia-reperfusion injury results from temporary cessation of coronary blood supply, a clinically relevant problem associated with thrombolysis, percutaneous coronary interventions, and coronary bypass surgery. In mice with myocardial ischemia-reperfusion injury, Kataoka et al. [26] found that, compared with normal IgG or saline administration LOX-1 inhibition by its antibody treatment resulted in a nearly $50 \%$ reduction in myocardial infarct size. Pretreatment with LOX-1 antibody in rats with ischemiareperfusion model, Li et al. [27] reported that LOX-1 inhibition prevented adhesion molecule expression and leukocyte recruitment. To further determine the role of LOX-1 in ischemia-reperfusion injury to the heart, Hu et al. [28] subjected wild type and LOX-1 knockout mice to $60 \mathrm{~min}$ of left coronary artery occlusion followed by $60 \mathrm{~min}$ of reperfusion, which found that LOX-1 knockout resulted in a significant reduction in myocardial injury and in accumulation of inflammatory cells. Nucleotide polymorphisms (SNPs), a missense mutation of LOX1 protein, is also involved in myocardial infarction [29].

Besides myocardial ischemia-reperfusion, hypertension is another major factor in the development of atherosclerosis. Renin-angiotensin system (RAS) activation has been suggested to play an important role in the pathogenesis and evolution of hypertension. As the key product of the RAS activation, angiotensin II has two main receptors: type 1 receptor (AT1R) and type 2 receptor (AT2R). In vitro, angiotensin II elevated LOX-1 expression in both endothelial cells and smooth muscle cells, but this elevation can be blocked by angiotensin-converting enzyme inhibitors and AT1R blockers [30,31]. In vivo, compared with
WT mice, LOX-1 knockout mice reveal decreased blood pressure and attenuated cardiac hypertrophy following long-term angiotensin II infusion [32].

It has been proposed that LOX-1 is an attractive target for the therapy of a number of cardiovascular disease states. Some investigators have described substrate mimics or natural inhibitors that inhibit LOX-1 activity, albeit in large concentrations. With an antagonist of LOX-1 receptor that modified oxidized phospholipid named PLAzPC, Falconi et al. [33] found that PLAzPC has high inhibiton of ox-LDL binding to LOX-1. Further chemical analysis showed that PLAzPC completely disables the hydrophobic component of the ox-LDL recognition domain, indicating that PLAzPC may be an attractive therapeutic molecules to anti-LOX-1. Similar to ox-LDL, acetyl-LDL also can be degraded by scavenger receptors, including LOX-1. With cultured macrophages, Yoshiizumi et al. [34] found that, as an analogue of LOX-1,2,4-bis benzenesulfonic acid sodium salt showed significant inhibitory activity against uptake of acetylLDL by macrophages. Statins are a class of cholesterol lowering drugs that often prescribed by doctors to anti-atherosclerosis. With human coronary artery endothelial cells, we found that two different statins, simvastatin and atorvastatin significantly inhibited ox-LDL induced LOX-1 expression [35]. Further study showed that both simvastatin and atorvastatin inhibited LOX-1 mediated adhesion molecule expression, such as vascular cell adhesion molecule-1 (VCAM-1) and intercellular Adhesion Molecule 1 (ICAM-1). Consistently, with molecular docking simulation, Biocca et al. [36] found that four types of statins, atorvastatin, fluvastatin, lovastatin and pravastatin could bind C-type lectin-like recognition domain of LOX-1, and further impaired LOX1 receptor activity. Amati et al. [37,38] utilized Schizophyllan (SPG), a polysaccharide that belongs to the $\beta-(1-3)$ glucan family, to inhibit LOX-1 gene and proposed it as a possible treatment for atherosclerosis. Using RAW 264.7 cells, they found that even the lowest concentration of SPG tested was able to inhibit the expression of LOX-1. In the apolipoprotein E knockout mice, they found that, compared with phosphate-buffered saline group, mice treated with SPG had a $63 \%$ reduction in the LOX-1 protein level in aortas. Nishizuka et al. [46] identified inhibitors from food extracts and found that procyanidins inhibited ox-LDL uptake in CHO cells expressing LOX-1 as well as the uptake of ox-LDL. Recently, using virtual screening techniques, our group identified several small molecule inhibitors of LOX-1 and tested their inhibitory potential using differential scanning fluorimetry and cellular assays. Two of these molecules significantly reduced the uptake of ox-LDL by human endothelial cells, LOX-1 transcription and the activation of extracellular-signal-regulated kinases $1 / 2$ (ERK1/2) and p38 mitogen-activated protein kinases (MAPKs) in human endothelial cells. In addition, these molecules suppressed ox-LDL-induced vascular cell adhesion molecule 1 (VCAM-1) expression and monocyte adhesion onto human endothelial cells demonstrating their therapeutic potential.

\section{Clinical implications}

LOX-1 biology and LOX-1 based therapy have been studied for near 20 years, the existing evidence indicate that LOX-1 is a potential target to treat ox-LDL mediated athero-thrombosis. Some cadiovasluar diseases, such as hypertension, atherosclerosis, myocardial infarction, thrombosis and coronay restenosis that shown in Figure 1, are mediated by LOX-1 activation. LOX-1 inhibition by its antibody, chemical analogue or siRNA transfection makedly improves cellular functions and reduces the probability formation of atherosclerotic lesion, hypertension and myocardial ischemia injury, suggesting that 


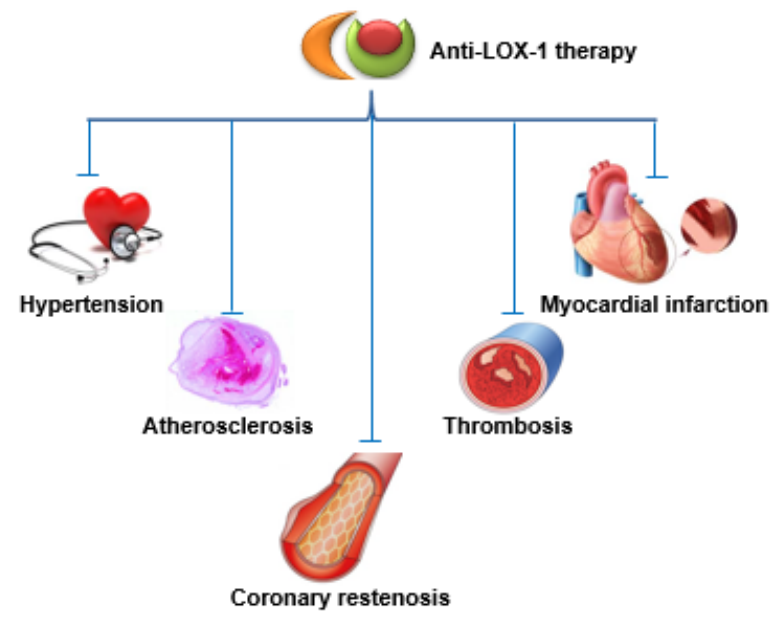

Figure 1. Potential targets for LOX-1 based therapy for cardiovascular diseases, such as hypertension, myocardial infarction, atherosclerosis, thrombosis and coronary restenosis.

targeting LOX-1 is becoming an attractive strategy for modulating the progression of these cardiovascular diseases, which may translate into clinical applications.

\section{Acknowledgments}

This study was supported by funds from the Department of Veterans Affairs, Veterans Health Administration, Office of Research and Development, Biomedical Laboratory Research and Development, Washington, DC. Additional support was provided by Grants-inAid from the National Natural Science Foundation of China (No. 11332003, 61190123).

\section{Conflict of interest}

None declared.

\section{References}

1. Sawamura T, Kume N, Aoyama T, Moriwaki H, Hoshikawa H, et al. (1997) An endothelial receptor for oxidized low-density lipoprotein. Nature 386: 73-77. [Crossref]

2. Ding Z, Wang X, Schnackenberg L, Khaidakov M, Liu S, et al. (2013) Regulation of autophagy and apoptosis in response to ox-LDL in vascular smooth muscle cells, and the modulatory effects of the microRNA hsa-let-7 g. Int $J$ Cardiol 168: 1378-1385. [Crossref]

3. Ding Z, Liu S, Wang X, Dai Y, Khaidakov M, et al. (2014) LOX-1, mtDNA damage, and NLRP3 inflammasome activation in macrophages: implications in atherogenesis. Cardiovasc Res 103: 619-628. [Crossref]

4. Kang BY, Hu C, Prayaga S, Khaidakov M, Sawamura T, et al. (2009) LOX-1 dependent overexpression of immunoglobulins in cardiomyocytes in response to angiotensin II. Biochem Biophys Res Commun 379: 395-399. [Crossref]

5. Ding Z, Liu S, Wang X, Khaidakov M, Dai Y, et al. (2015) Lectin-like ox-LDL receptor-1 (LOX-1)-Toll-like receptor 4 (TLR4) interaction and autophagy in CATH.a differentiated cells exposed to angiotensin II. Mol Neurobiol 51: 623-632. [Crossref]

6. Ding Z, Liu S, Wang X, Khaidakov M, Dai Y, et al. (2013) Oxidant stress in mitochondrial DNA damage, autophagy and inflammation in atherosclerosis. Sci Rep 3: 1077. [Crossref]

7. Nagase M, Abe J, Takahashi K, Ando J, Hirose S, et al. (1998) Genomic organization and regulation of expression of the lectin-like oxidized low-density lipoprotein receptor (LOX-1) gene. J Biol Chem 273: 33702-33707. [Crossref]

8. Ding Z, Liu S, Wang X, Khaidakov M, Fan Y, et al. (2015) Lectin-like oxidized lowdensity lipoprotein receptor-1 regulates autophagy and Toll-like receptor 4 in the brain of hypertensive mice. J Hypertens 33: 525-533. [Crossref]

9. Rudijanto A (2010) Calcium channel blocker (diltiazem) inhibits apoptosis of vascular smooth muscle cell exposed to high glucose concentration through lectin-like oxidized low density lipoprotein receptor-1 (LOX-1) pathway. Acta Med Indones 42: 59-65. [Crossref]

10. Li D, Mehta JL (2009) Intracellular signaling of LOX-1 in endothelial cell apoptosis. Circ Res 104: 566-568. [Crossref]

11. Ding Z, Liu S, Wang X, Deng X, Fan Y, et al. (2015) Hemodynamic shear stress via ROS modulates PCSK9 expression in human vascular endothelial and smooth muscle cells and along the mouse aorta. Antioxid Redox Signal 22: 760-771.

12. Ding Z, Liu S, Wang X, Deng X, Fan Y, et al. (2015) Cross-talk between LOX-1 and PCSK9 in vascular tissues. Cardiovasc Res 107: 556-567. [Crossref]

13. Libby P, Ridker PM, Maseri A (2002) Inflammation and atherosclerosis. Circulation 105: 1135-1143. [Crossref]

14. Honjo M, Nakamura K, Yamashiro K, Kiryu J, Tanihara H, et al. (2003) Lectin-like oxidized LDL receptor-1 is a cell-adhesion molecule involved in endotoxin-induced inflammation. Proc Natl Acad Sci U S A 100: 1274-1279. [Crossref]

15. Kelly KJ, Wu P, Patterson CE, Temm C, Dominguez JH (2008) LOX-1 and inflammation: a new mechanism for renal injury in obesity and diabetes. Am J Physio Renal Physiol 294: F1136-1145. [Crossref]

16. Shin HK, Kim YK, Kim KY, Lee JH, Hong KW (2004) Remnant lipoprotein particles induce apoptosis in endothelial cells by $\mathrm{NAD}(\mathrm{P}) \mathrm{H}$ oxidase-mediated production of superoxide and cytokines via lectin-like oxidized low-density lipoprotein receptor-1 activation: prevention by cilostazol. Circulation 109: 1022-1028. [Crossref]

17. Glick D, Barth S, Macleod KF (2010) Autophagy: cellular and molecular mechanisms J Pathol 221: 3-12. [Crossref]

18. Oka T, Hikoso S, Yamaguchi O, Taneike M, Takeda T, et al. (2012) Mitochondrial DNA that escapes from autophagy causes inflammation and heart failure. Nature 485 : 251-255. [Crossref]

19. Choy JC, Granville DJ, Hunt DW, McManus BM (2001) Endothelial cell apoptosis: biochemical characteristics and potential implications for atherosclerosis. $\mathrm{J} \mathrm{Mol} \mathrm{Cell}$ Cardiol 33: 1673-1690. [Crossref]

20. Ding Z, Liu S, Sun C, Chen Z, Fan Y, et al. (2013) Concentration polarization of oxLDL activates autophagy and apoptosis via regulating LOX-1 expression. Sci Rep 3: 2091. [Crossref]

21. Lu J, Yang JH, Burns AR, Chen HH, Tang D, et al. (2009) Mediation of electronegative low-density lipoprotein signaling by LOX-1: a possible mechanism of endothelial apoptosis. Circ Res 104: 619-627. [Crossref]

22. Takanabe-Mori R, Ono K, Sowa N, Wada H, Takaya T, et al. (2010) Lectin-like oxidized low-density lipoprotein receptor-1 is required for the adipose tissue expression of proinflammatory cytokines in high-fat diet-induced obese mice. Biochem Biophys Res Commun 398: 576-580. [Crossref]

23. Ding Z, Liu S, Deng X, Fan Y, Wang X, et al. (2015) Hemodynamic shear stress modulates endothelial cell autophagy: Role of LOX-1. Int J Cardiol 184: 86-95. [Crossref]

24. Sun Y, Chen X (2011) Ox-LDL-induced LOX-1 expression in vascular smooth muscle cells: role of reactive oxygen species. Fundam Clin Pharmacol 25: 572-579. [Crossref]

25. Mehta JL, Sanada N, Hu CP, Chen J, Dandapat A, et al. (2007) Deletion of LOX-1 reduces atherogenesis in LDLR knockout mice fed high cholesterol diet. Circ Res 100 1634-1642. [Crossref]

26. Kataoka K, Hasegawa K, Sawamura T, Fujita M, Yanazume T, et al. (2003) LOX-1 pathway affects the extent of myocardial ischemia-reperfusion injury. Biochem Biophys Res Commun 300: 656-660. [Crossref]

27. Li D, Williams V, Liu L, Chen H, Sawamura T, et al. (2002) LOX-1 inhibition in myocardial ischemia-reperfusion injury: modulation of MMP-1 and inflammation. $\mathrm{Am}$ J Physiol Heart Circ Physiol 283: H1795-1801. [Crossref]

28. Hu C, Chen J, Dandapat A, Fujita Y, Inoue N, et al. (2008) LOX-1 abrogation reduces myocardial ischemia-reperfusion injury in mice. $J$ Mol Cell Cardiol 44: 76-83. [Crossref]

29. Mango R, Clementi F, Borgiani P, Forleo GB, Federici M, et al. (2003) Association of single nucleotide polymorphisms in the oxidised LDL receptor 1 (OLR1) gene in patients with acute myocardial infarction. J Med Genet 40: 933-936. [Crossref]

30. Morawietz H, Rueckschloss U, Niemann B, Duerrschmidt N, Galle J, et al. (1999) Angiotensin II induces LOX-1, the human endothelial receptor for oxidized lowdensity lipoprotein. Circulation 100: 899-902. [Crossref]

31. Limor R, Kaplan M, Sawamura T, Sharon O, Keidar S, (2005) Angiotensin II increases 
the expression of lectin-like oxidized low-density lipoprotein receptor-1 in human vascular smooth muscle cells via a lipoxygenase-dependent pathway. Am J Hypertens 18: 299-307.

32. Lu J, Wang X, Wang W, Muniyappa H, Hu C, et al. (2012) LOX-1 abrogation reduces cardiac hypertrophy and collagen accumulation following chronic ischemia in the mouse. Gene Ther 19: 522-531. [Crossref]

33. Falconi M, Ciccone S, D'Arrigo P, Viani F, Sorge R, et al. (2013) Design of a novel LOX-1 receptor antagonist mimicking the natural substrate. Biochem Biophys Res Commun 438: 340-345. [Crossref]

34. Yoshiizumi K, Nakajima F, Dobashi R, Nishimura N, Ikeda S (2002) Studies on scavenger receptor inhibitors. Part 1: synthesis and structure-activity relationships of novel derivatives of sulfatides. Bioorg Med Chem 10: 2445-2460. [Crossref]
35. Li D, Chen H, Romeo F, Sawamura T, Saldeen T, et al. (2002) Statins modulate oxidized low-density lipoprotein-mediated adhesion molecule expression in human coronary artery endothelial cells: role of LOX-1. J Pharmacol Exp Ther 302: 601-605. [Crossref]

36. Biocca S, Iacovelli F, Matarazzo S, Vindigni G, Oteri F, et al. (2015) Molecular mechanism of statin-mediated LOX-1 inhibition. Cell Cycle 14: 1583-1595. [Crossref]

37. Amati F, Diano L, Vecchione L, Norata GD, Koyama Y, et al. (2012) LOX-1 Inhibition in ApoE KO Mice Using a Schizophyllan-based Antisense Oligonucleotide Therapy. Mol Ther Nucleic Acids 1: e58. [Crossref]

38. Nishizuka T, Fujita Y, Sato Y, Nakano A, Kakino A, et al. (2011) Procyanidins are potent inhibitors of LOX-1: a new player in the French Paradox. Proc Jpn Acad Ser B Phys Biol Sci 87: 104-113. [Crossref]

Copyright: (2016 Liu S. This is an open-access article distributed under the terms of the Creative Commons Attribution License, which permits unrestricted use, distribution, and reproduction in any medium, provided the original author and source are credited. 